\title{
Differentiated Instruction And The Need To Integrate Teaching And Practice
}

\author{
Huong L. Pham, Argosy University, USA
}

\begin{abstract}
Differentiated instruction is becoming critical in higher education due to student diversity and background knowledge. Differentiated instruction does not mean matching teaching styles with learning styles as suggested by the learning styles theory. Findings in recent research studies have proved the lack of credible evidence for the utility of the learning styles theory. As not scientifically proven, the theory serves to perpetuate the learning styles mythology in the educational psychology world.

This paper will emphasize students' readiness levels as a critical part of differentiated instruction that teachers should refer to rather than sticking to student preferences and/or learning styles. The paper also suggests strategies to differentiate instruction effectively. These strategies include, but are not limited to, identifying student readiness; making modifications of the instructional content, process, and product; and enhancing collaboration and autonomy in learning. The last part of the paper places an emphasis on the integration of teaching and practice. Differentiated instruction, at its best, should reflect a new pedagogy that can promote practical integration and knowledge transformation. If implemented thoroughly, differentiated instruction can demonstrate institutional effectiveness and equip students with diverse learning experiences to highly respond to increased challenges in the global society.
\end{abstract}

Keywords: Differentiated Instruction; Learning Styles; Student Readiness, Teaching and Practice Integration

\section{INTRODUCTION}

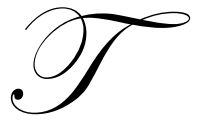

eaching in higher education is getting more challenging as student populations become more culturally, socially, and academically diverse. The purpose of higher education is to promote meaningful and engaging learning to help students prepare for future careers. Teachers bear responsibility for delivering knowledge associated with experiments and practices through service learning or experiential learning (Meyers, 2009; Strati, 2007). "One-size-fits-all instruction" does not work effectively due to student diversity in preferences and background knowledge, even if they are at the same age (Tomlinson, 2001). As students differ widely in nature, there are no right ways in teaching and learning methods. Progress rates may differ in the same group because of differences in student cognitive development, instructional strategies, and teaching materials that all have a strong impact on academic performance.

Differentiated instruction can become best productive by the use of "an eclectic mix of methods combined with wisdom, logic, a sound knowledge of educational psychology and seasoned artistry" (Orlich, Harder, Callahan, Trevisan, \& Brown, 2004, p.17). An eclectic approach allows teachers to consider a wide range of sources and to choose the ones that best fit their students. However, as noted by Brown and Green (2006), eclecticism can be of little effect since the combined methods may appear more complex for students to understand and "if not carefully considered, articulated, and evaluated, the 'linking science' that so many people worked to create might be seen as changing to a less rigorous, less 'scientifically sound' activity" (p. 21). In order to ensure successful outcomes, teachers need to be fully aware of students' cognitive development and readiness levels for the use of appropriate instructional techniques and strategies. 
Differentiated instruction, as discussed in this paper, places an emphasis on student readiness rather than diverse learning styles, which have not been scientifically proven in the existence so far. Also, it focuses on the integration of teaching and practice to offer students multiple options for taking in information and making sense of ideas. The integrated teaching and practice helps unfold learning experiences and encourage "formal recognition of knowledge produced through experimentation in educational practice" (Fenwick, 2004, p.43). At its best, teaching should focus on learning principles and their practical applications to connect what learners learn to real-world situations, a cornerstone for learners to learn, think, and grow together.

It is the purpose of this article to emphasize student readiness as a critical part of differentiated instruction rather than learning styles. The paper also suggests strategies to differentiate instruction effectively, as well as the need to integrate teaching and practice for enhanced intellectual knowledge and practical skills that certainly benefit learners to cope with increased challenges in the global society.

\section{DIFFERENTIATED INSTRUCTION IS NOT IN COMPLIANCE WITH LEARNING STYLES}

\section{Literature Review of Learner Preferences and the Appeal of Learning Styles Theory}

The learning styles theory suggests that different students have different modes of learning and instructional approaches should respond to diverse learning styles to maximize academic performance (Dunn, 2000). Learners have different ways of learning and thinking that make them distinct from others and study best in different ways. There is no correct approach to differentiate instruction and teachers may select different methods to create the best possible instruction. An effective teaching approach is to identify the ways in which learners learn best and design instructional strategies that correspond with situations and learner needs. An instructional strategy can be effective for a number of students but turn out ineffective for others due to diverse learning characteristics. If students are given responsive environments and instruction, they will probably attain more satisfactory results (Dunn, 2000; Tomlinson, 2001).This initiates the call for responsiveness and adaptability in instruction to address student diversity.

It is possible that learners can be categorized into three main types: visual learners, auditory learners, and kinesthetic learners (also called VAK learning styles - Clark, 2008; Tomlinson, 1999). Visual learners learn best through written language, pictures, charts, diagrams, videos, and other demonstrations. They have good visualization skills, remember what has been written down, and pay greater attention to other people's body language. Auditory learners prefer instruction and information to be presented verbally. They enjoy making contacts through verbal communications and participating in oral discussions. Kinesthetic learners, unlike the other two groups, greatly benefit from hands-on activities and work best when being engaged in role plays, scenario acts, lab experiments, or other movement activities. Kinesthetic learning is appropriate for those who want to become surgeons, athletes, actors/ actresses, and architects.

Learner diversity results from individual differences in ability and motivation, but environmental and developmental factors also affect the ability to learn (Gagné, Wager, Golas, \& Keller, 2005). Gagné et al. (2005) indicated that there are 14 learner-centered psychological principles that can be classified into four groups: cognitive and metacognitive, motivational and affective, developmental and social, and individual differences. These principles help contribute to internal qualities of learners and affect the information processing and cognitive thinking process. Among the 14 learning style principles, some learners are affected by many principles while others only a few, thus a single or dual dimensional model may not include the principles that produce the most significant gains for individual learners (Dunn, 2000). This encourages eclecticism in teaching approaches in which a typical lesson plan should combine elements from various sources to provide learners with comprehensible input for the presentation of new structures.

Due to differences in cognitive development, learners perceive, organize, and retain information differently. Learning goes through a number of processes, from processing information to short-term memory before transforming the encoded information to long-term memory (Gagné et al., 2005). The information, when restored, generates a stimulus response or action and translates into knowledge, skills, and attitudes that can be observed in the learning process (Brown \& Green, 2006; Gagné et al., 2005; Oliva, 2009). As the information is processed 
differently among different learners, it is necessary to make lessons accessible to learners in a multitude of ways. If instruction does not result in anticipated outcomes, teachers then should make necessary adjustments to attain predetermined goals and objectives.

Obviously, people have different preferences and interests in learning. While a number of students prefer a certain mode of delivery, others are interested in other ways of presentation. Nevertheless, the concept of learning styles tends to lose its utility in educational practices due to the lack of scientific evidence. Matching instruction to student strengths and preferences, as noted by educators and researchers nowadays, does not guarantee academic success (Pashler, McDaniel, Rohrer, \& Bjork, 2008; Riener \& Willingham, 2010; Scott, 2010). Instead, student readiness is "a critical consideration in the optimization of instruction... an individual student's prior knowledge is bound to determine what level and type of instructional activities are optimal for that student." (Pashler et al., 2008, p.108) Differentiated instruction, with an aim to gain its optimal efficiency, should not be based on student preferences. It is, however, an excellent way to address students' readiness levels and improve their weaknesses in a course setting. This idea will be further developed in the later part of the article.

\section{Learning Styles Theory: The Lack of Evidence}

While there is ample literature review supporting the learning styles theory and the need to differentiate instruction based on learning styles, there are notions against the theory. In the book entitled, "50 Great Myths of Popular Psychology: Shattering Widespread Misconceptions about Human Behavior", the authors indicated that it is a misconception to assume that students learn best when teaching styles are matched to learning styles (Lilienfeld, Lynn, Ruscio, \& Beyerstein, 2009). The authors stated four reasons for this conceptual flaw. First, there is not a clear concept of learning styles. There are varying models to refer to a learning style, e.g., the VAK model, the Multiple Intelligences model, or other models based on activists, theorists, pragmatists, etc., which make scholars hold different ideas about a learning style and there has been no consensus on its definition. Second, there are no reliable and valid methods to assess learning styles, which are usually placed in devoid settings. In other words, there is no relationship between learning style classifications and their memory performance. For example, visual learners did not do better than auditory and kinesthetic learners when receiving visual modes of delivery. Third, adopting an innovative teaching method different from students' ordinary styles may yield more striking outcomes than the one matched to their learning styles. It is necessary for teachers to correct and compensate for learners' shortcomings rather than to address their strengths solely. Matching teaching styles to learning styles just avoids learners' weaknesses, thus these weaknesses cannot be identified and may grow weaker. Forth, few well-conducted research studies have provided evidence and positive results for learning styles. They have not been scientifically proven in the existence so far.

Findings in research studies have also added to the lack of learning styles existence. A research study conducted by Pashler et al. (2008) found no evidence to support the fact that students receiving instruction tailored to their preferences would outperform those who did not receive tailored instruction. These researchers found that providing different groups of students with different forms of instruction according to their interests did not maximize their performance on any single test. Similarly, other studies further supported the evidence that there was not a significant interaction between learning styles and instructional versions (Cook, Gelula, Dupras, \& Schwartz, 2007; Hsieh \& Dwyer, 2009). In other words, varying types of instruction did not produce effective outcomes on different learners. Literature also shows that learners may have different preferences but adapting to these preferences and individual attributes does not result in academic improvement, thus the validity of learning styles applied to classroom contexts is not warranted (Riener \& Willingham, 2010; Scott, 2010). Teachers should, therefore, present information in the most appropriate manner based on students' backgrounds, prior knowledge, and abilities rather than learning styles.

In general, differentiated instruction gives students opportunities for taking in information and making sense of ideas in the most effective and preferred way. As the learning styles theory is not scientifically proven, it serves to perpetuate the learning styles mythology in the educational psychology world. The bottom line of differentiated instruction, therefore, is not to match instructional strategies to learning styles but to identify students' readiness levels to adjust instruction for academic success. For example, teachers may select direct instruction for low performing students while it is more appropriate to apply self-directed or independent learning for high performing students. 


\title{
HOW TO DIFFERENTIATE INSTRUCTION EFFECTIVELY?
}

\author{
Identifying Students' Readiness Levels
}

Since student diversity is enormous in scope and students possess varying cultural and psychological characteristics, their educational backgrounds are not similar. As mentioned, differentiated instruction should be associated with the identification of student readiness to help teachers deliver lessons in an effective manner. Identifying academic backgrounds is an essential factor to create productive interventions that can address student weaknesses. This can be conducted through achievement tests, performance assessment, oral presentations, writing assignments, and student portfolios (Lyons, McIntosh, \& Kysilka, 2003). Student performance should be assessed before, during, and after the instructional process to measure student progress and to ensure if lesson objectives are achieved. Field experience and service learning should be included in the assessment to support students to develop interdisciplinary awareness in real-life circumstances.

Effective teachers can recognize individual and group differences among students and adapt instruction to shorten achievement gaps. Stronge (2007) indicated that the adaptation of instruction requires teachers to involve "careful assessment and planning for all students in the classroom, as well as the ability to select from a range of strategies to find the optimal match to the context." (p. 70) Indeed, effective adaptation requires teachers to flexibly design strategic lesson plans, conduct regular assessment, and make adjustments in a timely manner to retain students' continued engagement. Teachers also adapt instruction to meet the needs of students who either perform highly or lowly or those who will certainly make progress if receiving different types of presentation.

\section{Modifying the Instructional Content, Process, and Product}

Tomlinson (1999) indicated that differentiated instruction includes modifying the content, the process, and the product of instruction. The content should be challenging but manageable, otherwise students fall behind and stay discouraged. This principle matches Vygotsky's Zone of Proximal Development (ZPD), which is defined as a discrepancy between a learner's actual mental age and the level that he/she can reach in the field (Bigge \& Shermis, 2004). Modifying the content is effective if it complies with one's developmental progress and in the range of his/her development. Additionally, content modification should emphasize key dimensions of instruction for desired learning outcomes. Focusing on the essentials of instruction is one of the principles that teachers should bear in mind for effective differentiation. Learners tend to forget more than remember every piece of information, thus the selection of what kind of information to be presented helps reduce significant time and efforts yet maintain effective results.

Modifying the instructional process, on the other hand, involves applying varying activities, techniques, and teaching strategies to help learners make sense of meaning and understand underlying principles. This requires teachers to organize instruction in a logical sequence from easy to difficult, concrete to abstract, simple to complicated levels of understanding (Brown \& Green, 2006; Gagné et al., 2005). Experienced teachers can employ strategic methods to communicate the lesson content to learners in the most comprehensible manner, no matter how challenging it is. The main objective of modifying the instructional process is to make every single lesson meaningful and applicable to learners in an academically enriched context. Finally, modifying the product refers to the evaluation of what learners understand and how well they can understand a concept. This can be assessed by different forms of assignments, in which learners can reflect what they have learned and how they can apply theoretical concepts to practical situations. Assessment should include what students have been taught during instruction and should be conducted on a regular basis with feedback provided to students promptly.

\section{Enhancing Both Collaborative Learning and Autonomous Learning}

Since students are culturally and academically diverse, differentiated instruction should facilitate learning through enhanced collaboration for students to exchange cultural and social values in a supportive learning community (Nordlund, 2003). In addition, students should be given opportunities to explore new knowledge and develop a critical understanding of the subject matter through independent learning. By focusing on both collaboration and autonomy, differentiated instruction can accommodate a wide range of students who are either at a 
low level and need intensive support or at a high level and need their skills sharpened. Brown \& Green (2006) recommended that effective instruction should develop students' cognitive thinking and offer them opportunities to critically explore and "focus on the concepts to be learned instead of the steps involved in completing a specific task." (p. 172) Also, teachers can strengthen the success of student learning by asking if/then questions (e.g., If we want students to perform in this manner, then they need to learn these skills) to visualize the outcomes and develop a sequence of viable steps to support students to reach desired objectives (Oliva, 2009). If learning does not occur in an expected manner, teachers should conduct assessment and modify instruction to achieve predetermined goals.

Differentiated instruction is efficient if it can bring about expected changes in student learning. Identifying students' background knowledge is of critical importance as it requires teachers to determine what types of intervention are needed and how much support should be offered to students. Additionally, modifications in the instructional content, process, and product can support students to grasp key aspects of instruction in the most effective way, as well as evaluate student performance accurately. Also important is the employment of learning collaboration and autonomy that can develop student interactions and communication skills but at the same time offer them practice of independent learning. These factors can serve as an efficient framework for differentiated instruction to maximize student learning for the achievement of knowledge, skills, and attitudes.

\section{THE NEED TO INTEGRATE TEACHING AND PRACTICE}

Changes in economic, social, and political aspects require innovations in education. As more highly qualified skills and intellectual work are required, making changes in education becomes a priority to respond to social demands. Differentiated instruction, at its best, should reflect a new pedagogy that can promote practical integration and knowledge transformation. Students should be equipped with diverse learning experiences that allow them to expand their conceptual understanding and apply theoretical knowledge to practical situations. The success of higher education, as stated by Aggarwal (2008), is to incorporate "soft skills", e.g., effective writing, oral communications, presentations, and problem-solving, into curriculums to adapt to knowledge transformation and expose students to real-life settings. Differentiated instruction should prepare learners for a smooth transition from the world of academia to the world of work through a new learning model not just to respond to student diversity but also to align with high social demands.

As pointed out by Fenwick (2004), one of the critical factors to initiate practice-based curriculums is to ensure teacher professional growth. The ability to adapt teaching practices depends on how well teachers keep informed about educational trends and what they are supposed to do to deal with such changes. Jenlink (2005) emphasized that teachers in higher education should act the role as "scholar practitioners" who need to develop an interdisciplinary understanding that is responsive to changes and that "requires more than a causal understanding of the theories, philosophies, methods, and processes of many disciplines" (p. 5). Scholar practitioners now acknowledge the need to extend their reach to other disciplines rather than to limit their knowledge to one subject matter. The social and economic inequality leads to changes in education and requires educators to develop a broad understanding not just limited in classroom contexts but to reach out toward keeping up with social and educational changes. The challenge for educators is to learn new knowledge, develop interdisciplinary awareness, react to educational policies, and fulfill demanding goals so as to provide learners with a variety of skills to cope with increased challenges in reality.

Integrating teaching and practice also involves the reinvention of curriculum design based on the "knowledge-based economy". This emphasizes the collaboration between universities and entrepreneurs, the effects of market demands on curriculum designs and delivery methods, the pressures of the market economy on higher education administrators, and the shift in student positions from learners to customers (Lambert, Parker, \& Neary, 2007). Knowledge-based economy creates a spontaneous response to promoting educational links with the business industry. Curriculums may be reinvented by having international modules, e.g., multiculturalism, bilingualism, included in the program and emphasizing research as a more prestigious and financially deserved activity than teaching. Waks (2003) indicated that the globalization process has caused two fundamental changes in curriculums: changes in goals and objectives and changes in shaping and sequencing subject matters to better approach the new ends. Differentiated instruction should address these two changes by developing responsive lessons and applying relevant teaching methods that can foster the achievement of institutional goals and objectives. 
Findings in research studies have proved that integrating teaching and practice helps promote learning experiences and student interests in understanding how things are related with theories and how the combined theories and practices work together (Brodie \& Irving, 2007; Brook \& Lock, 2010; Brooks \& Everett, 2008). Learning models associated with theories and practices may bring about expected changes and reinforce student beliefs that experiential learning is a good way for them to learn new things, do a better job, achieve success through employment training, and get a professional accreditation.

Needless to say, changes in education are strongly impacted by changes in social, cultural, and political aspects. As a consequence, the successful integration of teaching and practice requires efforts not only from the school but also from related stakeholders such as entrepreneurs, parents, or policy makers. Effective changes depend on collaborative efforts and shared responsibility of different stakeholders that indirectly or directly affect student academic performance. Of all responsibilities is the greatest burden that teachers have to take to equip students with practical knowledge and skills for their successful career paths. Teachers should also ensure professional growth by extending their reach to interdisciplinary awareness to facilitate fundamental changes.

\section{CONCLUSION}

Differentiated instruction is obviously a beneficial teaching approach to address students' educational levels in a course setting. It is not a single arena, but a combination of conceptual orientation and practical application which helps students view a subject matter from a holistic account rather than a fragmented outlook, as well as develop a critical understanding about learning principles applied in real-life settings. Effective differentiation should include, but is not limited to, identifying students' readiness levels, modifying instruction, applying collaboration and autonomy in learning, and integrating teaching and practice to enhance learning. Differentiated instruction gives students tools and methods to be self-directed, creative, and contextually responsive to seek for knowledge by using core principles and concepts. Also, differentiated instruction gives students opportunities to learn in reflective and collaborative environments where they can develop a wide range of skills needed for their career success. Teachers not just apply a series of discrete instructional components when differentiating instruction, but need to see the connection among components and understand how things are related together to come up with the best teaching strategies, optimal analysis, and evaluation (Orlich et al., 2004). It is necessary to employ a multitude of teaching methods and activities to maximize academic success based on student readiness.

Last but not least, differentiated instruction is not just a matter of combining teaching and practice but more important is to reinvent curriculums to highly respond to social and economic changes. Equipping students with practical skills and competences requires teachers to take the role as scholar practitioners who should develop an interdisciplinary understanding to keep up with increased demands in the globalization process (Jenlink, 2005). The responsibility of teachers is not limited to teaching in traditional contexts, but to demonstrate responsiveness to the needs of society by incorporating learning and experiments astutely to orient learners to increased challenges in a global society.

\section{AUTHOR INFORMATION}

Huong L. Pham has worked as a teacher of English at the University of Economics and Law, an affiliate of Ho Chi Minh National University, Vietnam. Her Bachelor's degree is in English language teaching and Master's degree in Teaching English to Speakers of Other Languages (TESOL). She is currently a senior doctoral student in instructional leadership in higher education at Argosy University, San Francisco Bay Area, USA. Her interests include instruction/curriculum design and development, program evaluation, teaching and learning strategies, and educational research. She is also interested in cultural diversity and educational psychology. The author's email: huongpham@stu.argosy.edu or ptlanhuong2000@yahoo.com 


\section{REFERENCES}

1. Aggarwal, N. (2008). Changing economic landscape: Workplace environment and new demands. The International Journal of Learning, 15(9), 281-286.

2. Bigge, M., \& Shermis, S. (2004). Learning theories for teachers (6th ed.). Boston, MA: Pearson.

3. Brodie, P., \& Irving, K. (2007). Assessment in work-based learning: Investigating a pedagogical approach to enhance student learning. Assessment \& Evaluation in Higher Education, 32(1), 11-19.

4. Brook, C., \& Lock, G. (2010). Reflective practice, professional learning, and educational partnerships: Effecting change in classroom settings. In E. Ng (Ed.), Comparative blended learning practices and environments, (pp. 188- 203). Hershey, PA: IGI Global.

5. Brooks, R., \& Everett, G. (2008). The predominance of work-based training in young graduates' learning. Journal of Education and Work, 21(1), 61-73.

6. Brown, A., \& Green, T. (2006). The essentials of instructional design: Connecting fundamental principles with process and practice. Upper Saddle River, NJ: Pearson.

7. Clark, D. (2008). Visual, auditory, and kinesthetic learning style (VAK). Retrieved December 7, 2010, from http://www.nwlink.com/ donclark/hrd/styles/vakt.html

8. Cook, D., Gelula, M., Dupras, D., \& Schwartz, A. (2007). Instructional methods and cognitive and learning styles in web-based learning: Report of two randomized trials. Medical Education, 41(9), 897-905.

9. Dunn, R. (2000). Capitalizing on college students' learning styles: Theory, practice, and research. In S. Griggs \& R. Dunn (Eds.), Practical approaches to using learning styles in higher education (pp. 3-33). Westport, CT: Bergin \& Garvey.

10. Fenwick, T. (2004). The practice-based learning of educators: A co-emergent perspective. ScholarPractitioner Quarterly, 2(4), 43-59.

11. Gagné, R., Wager, W., Golas, K., \& Keller, J. (2005). Principles of instructional design (5th ed.). Belmont, CA: Wadsworth.

12. Hsieh, P., \& Dwyer, F. (2009). The instructional effect of online reading strategies and learning styles on student academic achievement. Journal of Educational Technology \& Society, 12(2), 36-50.

13. Jenlink, P. (2005). Editorial: On bricolage and the intellectual work of the scholar-practitioner. ScholarPractitioner Quarterly, 3(1), 3-12.

14. Lambert, C., Parker, A., \& Neary, M. (2007). Entrepreneurialism and critical pedagogy: Reinventing the higher education curriculum. Teaching in Higher Education, 12(4), 525-537.

15. Lilienfeld, S., Lynn, S., Ruscio, J., \& Beyerstein, B. (2009). 50 great myths of popular psychology: Shattering widespread misconceptions about human behavior. Malden, MA: Wiley- Blackwell.

16. Lyons, R., McIntosh, M., \& Kysilka, M. (2003). Teaching college in an age of accountability. Boston, MA: Pearson.

17. Meyers, S. (2009). Service learning as an opportunity for personal and social transformation. International Journal of Teaching and Learning in Higher Education, 21(3), 373-381.

18. Nordlund, M. (2003). Differentiated instruction: Meeting the educational needs of all students in your classroom. Lanham, MD: Scarecrow Press.

19. Oliva, P. (2009). Developing the curriculum (7th ed.). Boston, MA: Pearson.

20. Orlich, D., Harder, R., Callahan, R., Trevisan, M., \& Brown, A. (2004). Teaching strategies: A guide to effective instruction (7th ed.). Boston, MA: Houghton Mifflin.

21. Pashler, H., McDaniel, M., Rohrer, D., \& Bjork, R. (2008). Learning styles: Concepts and evidence. Psychological Science in the Public Interest, 9(3), 105-119.

22. Riener, C., \& Willingham, D. (2010). The myth of learning styles. Change, 42(5), 32-35.

23. Scott, C. (2010). The enduring appeal of "learning styles". Australian Journal of Education, 54(10), 5-17.

24. Strati, A. (2007). Sensible knowledge and practice-based learning. Management Learning, 38(1), 61-77.

25. Stronge, J. (2007). Qualities of effective teachers (2nd ed.). Alexandria, VA: Association for Supervision and Curriculum Development.

26. Tomlinson, C. (1999). Differentiated classroom: Responding to the needs of all learners. Alexandria, VA: Association for Supervision and Curriculum Development.

27. Tomlinson, C. (2001). How to differentiate instruction in mixed-ability classrooms (2nd ed.). Alexandria, VA: Association for Supervision and Curriculum Development. 
28. Waks, L. (2003). How globalization can cause fundamental curriculum change: An American perspective. Journal of Educational Change, 4(4), 383-418.

\section{NOTES}

